\title{
ESTILOS COGNITIVOS DE ESTUDANTES DE PSICOLOGIA: IMPACTO DA EXPERIÊNCIA EM INICIAÇÃO CIENTÍFICA
}

\author{
Karina Brunini Pitta** \\ Ligia Angeli Dias dos Santos* \\ Carolina de Aragão Escher** \\ Isabel Cristina Dib Bariani***
}

\begin{abstract}
Resumo
Esta pesquisa pretendeu verificar se há impacto das experiências em Iniciação Científica nos Estilos Cognitivos, segundo universitárias. A coleta de dados foi realizada com oito alunas de Psicologia, aplicandose uma escala e entrevistas. Os dados foram analisados quantitativa e qualitativamente. Constatou-se que: não há predominância dos Estilos quanto à área e modalidade de pesquisa; todos apresentaram Divergência de Pensamento e predomínio de Reflexividade de Resposta; a maioria concordou com os Estilos avaliados e considerou como positivos aqueles que se modificaram. As principais variáveis responsáveis pelas alterações foram: orientador, atividades e trabalho em grupo. Pode-se concluir que a Iniciação Científica é um dos fatores que interfere no desenvolvimento cognitivo dos estudantes.

Palavras-chave: Estudantes Universitários, Estilos Cognitivos, Iniciação Científica.
\end{abstract}

\section{COGNITIVE STYLES OF PSYCHOLOGY COLLEGE STUDENTS: IMPACT OF SCIENTIFIC INITIATION}

\begin{abstract}
This study intended to veriry if Scientific lnitiation experience can cause impact in the Cognitive Styles of undergraduates. The subjects were eight female psychology students, who were submitted to a scale and interviews. The data was analysed qualitative and quantitatively. The results were: there is not a Cognitive Style predominance depending on the area and types of research, everybody presented Divergence Thinking and the majority is Reflexive, most subjects agree with the Style showed, and considering positives the ones that were modified. The variables detached as responsible for the changes were: own teacher, activities and work group. It is possible to say that Scientific lnitiation is one factor that can affect Cognitive developrnent of students.
\end{abstract}

Key words: Undergraduates Students, Cognitive Styles, Scientific Initialion.

\section{INTRODUÇÃO}

Por Estilo Cognitivo entende-se as diferenças individuais nas propriedades da estrutura cognitiva, que podem variar de acordo com a história de vida e que, conseqüentemente, vão determinar o modo pelo qual, habitualmente, as experiências e informações são organizadas e

\footnotetext{
* Bolsistas de Iniciação Científica - PUC-Campinas

** Auxiliar de Pesquisa - PUC - Campinas

*** Doutora em Educação e Professora do Instituto de Psicologia e Fonoaudiologia da PUC-Campinas Endereço para correspondência: PUC-Campinas. Instituto de Psicologia e Fonoaudiologia. Rua Marechal Deodoro, 1117, Centro, CEP 13020-904.Campinas, SP.e-mail: dbariani@lIol.com.br
} 
processadas, bem como vão orientar as soluções de problemas e tomada de decisões, influenciando, assim, a personalidade das pessoas (Messick, 1984; Riding e Wright, 1995; Tennant, 1988 apud Riding e Staley, 1998; e Sternberg e Grigorenko, 1997).

De acordo com Santos, Bariani e Cerqueira (1998), os Estilos Cognitivos indicam tendências básicas, variáveis quanto à forma de assimilar os dados da realidade, relacioná-los e tirar conclusões sobre eles; o que confere a cada indivíduo, interesses, valores, motivações, padrões de conduta e outras particularidades.

Ademais, Bariani (1998) destaca que os Estilos Cognitivos, além de serem características da estrutura cognitiva do indivíduo, também são modificados direta ou indiretamente pela influência de novos eventos, como os fatores biológicos, a própria cultura e as experiências de vida.

É importante destacar que existem outras definições que explicam os Estilos Cognitivos em sua forma geral, porém nenhuma delas abrange todas as características identificadas. Algumas incluem fatores psicológicos, de personalidade e de meio ambiente, tomando assim uma posição ec1ética; enquanto outras englobam apenas fatores psicológicos, conforme apontado por Santos, Bariani e Cerqueira (1998). Por essa razão, toma-se difícil obter uma definição mais precisa.

Entretanto, diferentes autores, com base em alguma dessas concepções, identificam várias dimensões de Estilos Cognitivos, apresentadas dicotomicamente, tais como: Verbal X Imaginativo, Campo Independente X Campo Dependente, Holista X Serialista, Associação Remota X Diferenciação, Impulsividade de Resposta X Reflexividade, Concreto X Abstrato, Convergência de Pensamento X Divergência, etc.

Serão adotadas neste estudo as quatro dimensões focalizadas por Bariani (1998):

\section{Campo ca. independente $X$ Campo Dependente}

Campo Dependente - este Estilo Cognitivo caracteriza indivíduos que requerem reforçamento extrínseco em suas atividades e têm como base uma estrutura externa de referência; assim, optam por conteúdos e seqüências preestabelecidos. Preferem trabalhar em grupo e atribuem importância a uma interação informal no ambiente escolar (relação professor-aluno); no entanto, apresentam dificuldades em fazer avaliações críticas.

Campo Independente - característica própria de indivíduos que tomam como base estruturas internas de referência e, por isso, optam por participar da organização de conteúdos e seqüências. Preferem trabalhar individualmente e se importam mais com o conteúdo do que com a interação professor-aluno. Não apresentam dificuldades em fazer análises críticas referentes às outras pessoas.

\section{Impulsividade de Resposta X Reflexividade}

Impulsividade de Resposta - característica comum às pessoas que costumam responder sem uma prévia reflexão. Não dão importância à ponderação e à organização que precede a ação.

Reflexividade de Resposta - diz respeito às pessoas que se atêm mais às ponderações e organizações que antecedem uma resposta. Seus pensamentos são mais ordenados e contínuos.

\section{Convergência de Pensamento $X$ Divergência}

Convergência de Pensamento - constitui um aspecto que identifica indivíduos, cujo pensamento obedece ao raciocínio lógico e que têm habilidades para lidar com questões que exigem 
uma solução determinada a partir das informações forneci das. Têm mais facilidade em trabalhar com tarefas mais convencionais e estruturadas, que requerem lógica. São pessoas disciplinadas, acomodadas e conservadoras.

Divergência de Pensamento - é relativo à imaginação, criatividade, originalidade e fluência. São indivíduos que apresentam pouca sociabilidade. Trabalham melhor com problemas menos estruturados, que requerem quantidade, variedade, originalidade e generalidade das respostas.

\section{Holista X Serialista}

Holista - caracteriza aqueles que analisam uma tarefa sob o ponto de vista global, tentando estabelecer relações entre suas partes com a elaboração de hipóteses complexas.

Serialista - são os indivíduos que trabalham com um problema, partindo de aspectos específicos e separados, que posteriormente serão integrados para a confirmação ou refutação de hipóteses simples, as quais "passo a passo" vão possibilitar a resolução de um problema.

Na literatura nacional são escassas as investigações sobre este assunto; porém, em outros países, um grande número de pesquisas foi e vem sendo realizado com o objetivo de investigar os Estilos Cognitivos, relacionando-os com aspectos sociais, ambientais e educacionais, entre outros.

Estudos desta natureza são importantes, pois é possível afirmar-se que os Estilos são relevantes na trajetória educacional, bem como na vida das pessoas. Em relação ao processo ensinoaprendizagem nas escolas, sua influência é prevista em, pelo menos, quatro aspectos: o planejamento de currículos, os métodos instrucionais, os métodos de avaliação e a orientação a estudantes.

Em especial, a literatura internacional apresenta muitos estudos que têm buscado relacionar os Estilos Cognitivos a diversos aspectos educacionais (conforme pode ser verificado na revisão da literatura realizada por Bariani, 1998), mas poucos se propõem a investigar os Estilos Cognitivos relacionando-os à atividade científica.

Um exemplo de pesquisa com este objetivo é a que foi realizada por Haim (1981), na qual ele procurou determinar a extensão em que os estilos de pesquisa podem ser responsáveis pelas ideologias acadêmicas, no que se refere aos interesses dos universitários e do corpo docente. A amostra constituiu-se de 3.536 pesquisadores das áreas de Sociologia, Psicologia, Ciência Política e Educação. A estes foram atribuídos quatro campos que identificam seus estilos de pesquisa: básica ou não básica, política ou não política, aplicada ou não aplicada, experimental ou não experimental e quantitativa ou qualitativa (alguns desses estilos foram baseados num questionário chamado LappLipset, bem como outros itens relativos à ideologia acadêmica). A hipótese era de que os pesquisadores bem-sucedidos, em todas as quatro áreas, eram inclinados a adotar uma atitude conservadora em relação aos interesses do estudante e dos colegas. Em oposição, os pesquisadores com menos sucesso tenderiam a tomar atitudes favorecedoras de mudanças. Os resultados confirmaram essas hipóteses, principalmente dentre os docentes da Psicologia e menos nas outras áreas. Talvez isso tenha ocorrido devido ao fato das subáreas não terem sido investigadas (o peso e a influência de algumas delas podem modificar a percepção sobre todo o campo) ou ao tipo de medida escolhido, ou ainda a uma falácia da analogia conceitual.

Um estudo encontrado na literatura nacional relacionado aos aspectos educacionais, porém enfatizando a Iniciação Científica (I.C.), é o de Bariani (1998), que buscou verificar se há variação na predominância dos Estilos Cognitivos em função do curso freqüentado, da experiência em I.C. e 
do tempo de experiência nos programas de I.C. Para tanto, os dados foram coletados por meio da aplicação de uma escala tipo Likert em 973 universitários dos cursos de Biologia, Psicologia e Arquitetura e Urbanismo. O instrumento da coleta de dados foi construído com a pretensão de avaliar quatro dimensões de Estilos Cognitivos: Dependência-Independência de Campo, Convergência-Divergência de Pensamento, Holista-Serialista e Impulsividade-Reflexividade de Resposta. De acordo com os resultados, os bolsistas de I.C. dos três cursos apresentam menos Convergência de Pensamento do que os demais alunos; entretanto, os de Psicologia são ainda mais Divergentes e, ainda, são menos Dependentes de Campo. Os dados obtidos indicam que o tempo de experiência em I.C. pode ser responsável pela diminuição da Dependência de Campo. Assim, Bariani aponta que a experiência em I.C. parece ser de grande importância para a modificação dos Estilos Cognitivos.

A relevância da experiência em I.C. do universitário também é ressaltada por Simão (1994) em vários aspectos, como na aquisição de atitudes, habilidades e conhecimentos, que serão fundamentais para o desenvolvimento de futuras atividades como pós-graduando, profissional do ensino e da pesquisa e como cidadão.

No que diz respeito ao profissional da pesquisa, Costa, em 1995, afirmou que a I.C. possibilita ao aluno exercitar a prática para aquisição do raciocínio lógico e a conviver com a dualidade teoria-prática; o que são indispensáveis para o desenrolar de uma pesquisa e conseqüentemente para a formação de um futuro pesquisador. Outro ponto interessante destacado por este autor é que a maioria dos alunos vinculada à I.C. tende a seguir carreira científica (alguns antes mesmo de concluir a graduação), o que os coloca em grande vantagem frente a outros que não fizeram I.C., devido ao contato prévio com a metodologia científica. E, tendo em vista que a formação do pesquisador dá-se no Mestrado e Doutorado, a I.C. certamente representa um passo importante nesta direção.

Considerando que os bolsistas de I.C. serão provavelmente os futuros cientistas, é relevante para a sociedade tomar conhecimento acerca dessas pessoas, o que se toma possível através de pesquisas. Neste sentido, o presente estudo poderá contribuir para o incremento do conhecimento nesta área, auxiliando, desse modo, outras investigações e a implementação de práticas já existentes.

Assim, mediante essas considerações, o objetivo geral desta pesquisa foi verificar, segundo a opinião de universitárias, se há impacto das experiências em I.C. em seus Estilos Cognitivos.

Quanto aos objetivos específicos, estes consistiram em:

1. Descrever os Estilos Cognitivos predominantes em alunas de Psicologia com experiência em I.C. e verificar a opinião destas sobre os estilos identificados. 2. Verificar se há variação nos Estilos Cognitivos dos universitários em função da área e da modalidade de pesquisa.

3. Verificar junto às bolsistas a possibilidade da influência da experiência em I.C. na modificação de seus Estilos Cognitivos.

4. Identificar possíveis fontes de alteração dos Estilos Cognitivos.

\section{Informantes}

A amostra constituiu-se de oito alunas da $5^{a}$ série do Curso de Psicologia, da Pontifícia Universidade Católica de Campinas (PUC-Campinas), com experiência em Iniciação Científica. A coleta de dados foi feita somente neste curso, porque é nele que há uma das maiores concentrações 
de bolsistas de LC. na instituição em questão. Foi utilizado como critério de seleção das informantes a experiência de no mínimo dois anos em Iniciação Científica, pois seria possível verificar, com mais segurança, se houve mudanças ou não nos Estilos Cognitivos das estudantes durante esse tempo. A opção pela 5" série justifica-se pelo fato de ser o último ano do curso de Psicologia, portanto, com maior probabilidade de se encontrar alunos com essa experiência e com maior tempo.

\section{Material}

Para a coleta de dados foi utilizado o instrumento construído por Bariani (1998) em sua pesquisa. Este é composto de forma mista, sendo a primeira parte um questionário para a obtenção de dados pessoais e a segunda uma escala de cinco pontos do tipo Likert, destinada à descrição de quatro dimensões de Estilos Cognitivos preferenciais de estudantes, a saber: Campo Dependente/Campo Independente, Impulsividade/ Reflexividade de Resposta, Convergência/Divergência de Pensamento e Holista/Serialista.

\section{Procedimento}

Primeiramente, as pesquisadoras foram até as salas de aula e fizeram a identificação dos sujeitos. Em seguida, o instrumento foi entregue a cada uma das alunas selecionadas, sendo solicitado que respondessem com atenção. Nesta ocasião foi marcada uma entrevista com cada estudante para a discussão dos dados obtidos por meio do instrumento.

A opção pela entrevista foi feita devido ao fato de que esta técnica possibilita a obtenção de uma flexibilidade maior no esclarecimento das perguntas e diversidade das respostas dadas pelos informantes (Gil,1991). O tipo de entrevista utilizado foi a focalizada, por ser indicada para grupos de pessoas que passaram por alguma experiência específica, no caso a Iniciação Científica.

As entrevistas foram realizadas tendo como base um roteiro previamente elaborado pelas entrevistadoras, no qual eram abordadas questões referentes à escala anteriormente aplicada. Desta forma, as informantes expressaram suas opiniões acerca dos Estilos Cognitivos dominantes, da concordância ou não com os resultados do instrumento, da possível alteração dos Estilos Cognitivos em função da experiência em Iniciação Científica e do benefício ou não da predominância dos Estilos Cognitivos nos trabalhos de pesquisa desenvolvidos na Iniciação Científica.

Foi entregue às estudantes, no início de cada entrevista, uma devolutiva composta por uma tabela que continha os resultados obtidos na escala - pontuação em cada item e média em cada Estilo Cognitivo - e um texto explicativo referente às definições de cada estilo avaliado. A tabulação das respostas à escala foi realizada conforme sua posição (de 1 a 5), a contar do primeiro ponto à esquerda da escala. Esses dados deram suporte às discussões durante as entrevistas, as quais foram gravadas mediante a permissão das informantes e, posteriormente, transcritas e submetidas à análise quantitativa e qualitativa.

\section{RESULTADOS E DISCUSSÕES}

Observando-se a Tabela 1, verifica-se que o tempo de experiência dos informantes em Iniciação Científica (I.C.) varia de dois a quatro anos. A concentração de pesquisas ocorre na área de Psicologia Escolar, seguida pelas áreas de Avaliação Psicológica e Psicologia Hospitalar. Quanto 
à modalidade de pesquisa foi privilegiada aquela que é tanto qualitativa como quantitativa.

Outro aspecto observado foi a não predominância dos Estilos Cognitivos em função da área e modalidade de pesquisa, provavelmente devido ao número reduzido de informantes e a diversidade do tempo de experiência.

Com base nos resultados do instrumento aplicado, constatou-se que todos os bolsistas apresentam predomínio de Divergência de Pensamento e a maioria de Reflexividade de Resposta. Quanto às dimensões de Estilo Cognitivo Dependência/Independência de Campo e Holista/Serialista, a predominância oscila entre um e outro polo destas dimensões, havendo uma pequena tendência nos estilos Dependência de Campo e Serialista. (Ver Tabela 2.)

Tabela 1 - Caracterização dos informantes quanto ao tempo de experiência (anos) em Iniciação

Científica, área e modalidade das pesquisas realizadas

\begin{tabular}{|c|c|c|c|}
\hline $\begin{array}{c}\text { Informantes } \\
\text { Experiência }\end{array}$ & $\begin{array}{c}\text { Tempo de } \\
\text { Pesquisa }\end{array}$ & $\begin{array}{c}\text { Área de } \\
\text { Pesquisa }\end{array}$ & Modalidade de \\
\hline I & 2 & Psicologia Escolar & Quantitativa/Qualitativa \\
\hline II & 4 & Avaliação Psicológica & Quantitativa/Qualitativa \\
\hline III & 2,5 & Psicologia Hospitalar e & Quantitativa \\
\hline & 3 & Avaliação Psicológica & \\
\hline IV & 3 & Psicologia Hospitalar & Quantitativa/Qualitativa \\
\hline & 2,8 & Psicologia Escolar & \\
\hline $\mathrm{V}$ & 2 & Psicologia Escolar & Qualitativa \\
\hline $\mathrm{VI}$ & & & \\
\hline & 2,9 & Psicologia Hospitalar e & \\
\hline $\mathrm{VII}$ & & Avaliação Psicológica & Quantitativa/Qualitativa \\
\hline & & & \\
\hline & & & \\
\hline
\end{tabular}

Bariani (1998) comparando os Estilos Cognitivos de bolsistas e não-bolsistas de Psicologia verificou que os bolsistas são menos Convergentes e menos Impulsivos. Estes resultados são confirmados no presente estudo. Porém, nas dimensões Holista/ Serialista e Dependência/Independência de Campo, Bariani constatou que os bolsistas são mais Holistas e mais Independentes de Campo, fato que diverge dos resultados aqui obtidos. 
Tabela 2 - Médias obtidas pelos Informantes em cada um dos Estilos Cognitivos

\begin{tabular}{c|c|c|c|c|c|c|c|c}
\hline \multirow{2}{*}{ Informantes } & \multicolumn{7}{c}{ Estilos Cognitivos } \\
\cline { 2 - 9 } & Divergente & Convergente & $\begin{array}{c}\text { Campo } \\
\text { Dependente }\end{array}$ & $\begin{array}{c}\text { Campo } \\
\text { Independente }\end{array}$ & Holista & Serialista & Reflexividade & Impulsividade \\
\hline I & 3,75 & 2,25 & 4,0 & 4,0 & 2,5 & 3,75 & 4,25 & 2,25 \\
\hline II & 3,0 & 2,0 & 4,25 & 3,5 & 2,75 & 3,5 & 3,0 & 3,0 \\
\hline III & 4,0 & 2,25 & 4,25 & 3,0 & 4,0 & 3,5 & 4,5 & 2,75 \\
\hline IV & 4,0 & 2,25 & 4,0 & 2,5 & 3,0 & 4,0 & 2,5 & 3,5 \\
\hline V & 4,25 & 1,75 & 2,75 & 3,5 & 3,5 & 3,75 & 3,75 & 1,75 \\
\hline VI & 4,0 & 2,0 & 3,75 & 3,0 & 3,25 & 3,25 & 3,5 & 2,0 \\
\hline VII & 3,75 & 1,75 & 3,5 & 3,75 & 4,0 & 3,25 & 4,0 & 2,5 \\
\hline VIII & 3,75 & 2,0 & 2,75 & 3,75 & 4,0 & 2,5 & 3,5 & 3,0 \\
\hline
\end{tabular}

Quanto à opinião dos bolsistas acerca dos Estilos Cognitivos avaliados por meio da escala, a maioria concordou com os resultados, sendo que os pontos de maior discordância foram a sociabilidade e a capacidade para fazer avaliações críticas, como pode ser notado nas frases a seguir:

"... em relação à sociabilidade eu sou meio diferente disso. Sou bastante sociável, prefiro trabalhos em grupos, mesmo em relação à Psicologia eu gosto muito de trabalhar em grupos, trabalhar Dinâmicas de Grupos, trabalho em equipe. Então, nesse ponto eu acho que não acertou muito."

"Agora dificuldade em fazer avaliações críticas eu discordo. Eu tenho facilidade inclusive, muitas vezes eu padeço por ter tanta facilidade (...) Muitas vezes eu não controlo minha crítica justamente pela impulsividade."

Uma hipótese que pode explicar essas discordâncias recai sobre a expectativa social: é esperado dos estudantes de Psicologia, sobretudo dos formandos, que eles possuam certas habilidades como a capacidade para fazer avaliações críticas e, em especial, o bom relacionamento interpessoal.

Em relação ao impacto da I.C. nos Estilos Cognitivos, a maioria dos estudantes disse que já tinha esses estilos predominantes e que a I.C. os acentuou, com destaque para Divergência de Pensamento e Reflexividade de Resposta, conforme é mostrado na Tabela 3 e identificado nas frases abaixo:

"... Aqui também. Eu acho que eu era muito mais impulsiva, falava mais as coisas sem pensar antes de entrar para a pesquisa. " 
Tabela 3 - Opinião das Estudantes sobre o Impacto da Iniciação Científica nos Estilos Cognitivos

\begin{tabular}{c|c|c|c|c}
\hline Estilo Cognitivo & Modificou & Não Modificou & Acentuou & Diminuiu \\
\hline Dependência de Campo & 0 & $\mathrm{I}$ & 4 & 0 \\
\hline Independência de Campo & 0 & 0 & 4 & 0 \\
\hline Convergência de Pensamento & 0 & 0 & 0 & 0 \\
\hline Divergência de Pensamento & 0 & 1 & 7 & 0 \\
\hline Holista & 0 & 2 & 2 & 0 \\
\hline Serialista & 1 & 1 & 4 & 0 \\
\hline Impulsividade de Resposta & 0 & 1 & 1 & 0 \\
\hline Reflexividade de Resposta & 1 & 0 & 6 & 0 \\
\hline Total & 2 & 6 & 27 & 0 \\
\hline
\end{tabular}

"Olha, em relação à Divergência de Pensamento, Dependência de Campo, Holista, eu acho que eles apenas se acentuaram e, assim, foi uma coisa que a 1. C. ajudou com que se concretizassem $e$ que realmente eu sempre fui muito assim."

Dos Estilos Cognitivos que se acentuaram ou se modificaram em função da I.C., todos foram avaliados como sendo positivos.

Esses dados corroboram os encontrados por Bariani (1998): a experiência em I.C. parece ser de grande importância para modificação dos Estilos Cognitivos.

No que se refere àquelas alunas que afirmaram que a I.C. não contribui para a alteração de seus Estilos Cognitivos, a explicação dada pelas estudantes foi que elas sempre apresentaram essas características.

Quando questionadas sobre a contribuição ou não dos Estilos Cognitivos dominantes para os trabalhos de pesquisa, a maioria enfatizou a contribuição de diversas formas. A seguir são apresentados trechos das entrevistas que demonstram este aspecto quanto a cada um dos Estilos. É importante destacar que o único Estilo não mencionado foi o Convergente devido ao fato de não aparecer como dominante em nenhuma das estudantes.

\section{-Serialista:}

"Eu acho que ajuda. Trabalhar assim, sabe com um problema, separando as coisas, eu também acho que me ajuda como bolsista poder pensar, depois englobar as coisas, mas saber passo a passo o que é que eu to fazendo é um negócio que me ajuda."

\section{-Holista:}

"Você não pode também perder de vista o conteúdo todo que essa pesquisa tá fazendo parte (...). Você pode se especificar porque a pesquisa não tem como ser uma coisa muito aberta, mas você não pode perder de vista o todo. Em relação a isto me contribui."

\section{-Divergência de Pensamento:}

"Quando você tem essa Divergência de Pensamento: imaginação, criatividade, originalidade, fluência, é bom pra você estar montando um projeto. Tá tendo novas questões para auxiliar a pesquisa. Ler um texto e sacar alguma coisa quando for estudar. Acho que nesse sentido ajuda."

\section{-Impulsividade de Resposta:}

"Às vezes você precisa agir por impulso, entendeu? Tem que fazer alguma coisa já e já pega as 
coisas e vai, depois você vê."

\section{-Reflexividade de Resposta:}

"Em relação à reflexividade de resposta é importante, porque você não pode sair por aí achando que a primeira conclusão que você fez é a mais óbvia, qualquer coisa, é a certa. Quer dizer, me ajuda no sentido de refletir a respeito de vários aspectos e tudo mais."

\section{-Independência de Campo:}

"Eu não tive tanto do reforçador externo. É como se eu tivesse introjetado algumas coisas que já tão aqui dentro de mim, então dá pra ter uma visão crítica de... contrária a determinado assunto. Sem medo de as pessoas não aceitarem minha posição. Eu acho que isso é muito mais você ter uma visão crítica das coisas, ter uma segurança para isso."

\section{-Dependência de Campo:}

"É, a Dependência de Campo eu acho que é um jeito bem de eu poder trabalhar em grupo, eu acho isso super legal, poder contar com uma equipe."

Apenas uma informante apontou para a não-contribuição dos Estilos Cognitivos dominantes para os trabalhos de pesquisa.

Dentre os fatores destacados pelas próprias estudantes como fontes de alteração dos Estilos Cognitivos encontram-se as atividades e os trabalhos realizados durante a experiência em I.C., como congressos por exemplo, os trabalhos em grupo e também o orientador:

"O orientador, assim, tem que bater o seu estilo com o dele, bater muito, sabe. Então eu acho que o orientador é fundamental, qualquer coisa, na Iniciação Científica, pra escrever um projeto, pra fazer mestrado, pra qualquer coisa."

Apesar de a maioria concordar com a influência do orientador para a alteração de seus Estilos Cognitivos, três estudantes apontaram o contrário. Embora a literatura não contemple o orientador como fator de alteração de Estilos Cognitivos, vários pesquisadores destacam a sua importância para o processo de pesquisar do aluno. Bettoi (1995) aponta que o bom relacionamento estabelecido entre orientador e aluno é condição favorecedora do pesquisar; Bariani e Dimárzio (1997) enfatizam a importância da orientação para o sucesso dos trabalhos de pesquisa; e Zakon (1989), por sua vez, afirma que ambos - orientador e aluno - se escolhem, a escolha é mútua.

Além disso, as informantes ainda destacam a necessidade de paridade de Estilos Cognitivos entre orientador e aluno:

"Então, eu nem sei qual o Estilo predominante da minha orientadora, assim, especificamente, mas eu acredito que talvez tenha uma compatibilidade nesse sentido, porque flui super gostoso, sabe quando flui bem? Eu acho que precisa ter uma... paridade de estilo mesmo!... eu acho que é fundamental."

Quanto a esse aspecto há diferentes concepções entre os autores. Alguns como Allison Hayes \& Davis (1994) defendem que a paridade de Estilos Cognitivos entre professor e aluno favorece o processo de ensino aprendizagem; por outro lado, autores como Thompson \& CrutcWow (1993) acreditam que são os Estilos variados entre professor e aluno que auxiliam este processo, visto que confere maior flexibilidade.

Os Estilos Cognitivos, ainda, foram ressaltados como determinantes para o ingresso na I.C., pois algumas características foram evidenciadas como necessárias para o desempenho do bolsista, como: determinação, praticidade, dinamismo, interesse, criatividade e independência.

A partir das entrevistas, pode-se, também, verificar os benefícios que a I.C. traz para a 
formação do aluno:

"Eu acho que uma das grandes possibilidades que a Iniciação Científica favorece é você crescer criticamente, você não ser só um mero receptor de informação. Você pensar, avaliar e aí propor coisas diferentes. Conseguir ter um outro olhar. Isso é muito bom."

Os benefícios da experiência em I.C. são destacados por vários autores (como por Simão, 1994) como sendo de grande importância para o desenvolvimento do aluno, como já descritos anteriormente.

Observou-se, ainda, que grande parte dos bolsistas entrevistada tem a pretensão de seguir carreira como pesquisador, fazendo mestrado e doutorado.

Este resultado confirma os dados fornecidos por diferentes autores, como Costa (1995) e Bariani e Dimárzio (1997), que afirmam que os alunos de Iniciação Científica tendem a seguir carreira acadêmica, devido ao contato prévio e contínuo com a prática científica. Assim sendo, a Iniciação Científica representa um grande passo nessa direção.

\section{CONCLUSÕES}

A partir dos resultados desta pesquisa, torna-se possível concluir que, em relação aos Estilos Cognitivos das bolsistas de I.C., houve uma predominância mais acentuada da Reflexividade de Resposta e da Divergência de Pensamento e, também, uma tendência à Dependência de Campo e ao Serialismo. A maioria concordou com os Estilos avaliados, havendo divergência somente quanto a dois aspectos: sociabilidade e capacidade para fazer avaliações críticas. Constatou-se, também, que não houve variação nos Estilos Cognitivos das universitárias em função da área e modalidade de pesquisa.

Embora tenha se trabalhado com um pequeno número de informantes, o que impossibilita a generalização dos resultados obtidos, este estudo permitiu verificar que, quanto à possibilidade da experiência em I.C. influir na modificação dos seus Estilos, as estudantes indicam haver uma tendência a acentuar os já existentes, destacando os seguintes fatores como contribuintes: orientador, atividades e trabalhos realizados na própria I.C. e os trabalhos em grupo. Um outro aspecto relevante é que embora haja a possibilidade de modificação dos Estilos Cognitivos em função da I.C., parece que os alunos que ingressam nos programas de Iniciação Científica já apresentam características diferenciadas daqueles que não vivenciam esta experiência, o que está de acordo com Bariani, 1998.

Diferentes autores, citados no decorrer deste trabalho, partindo do pressuposto de que os Estilos Cognitivos são características relativamente estáveis, mas que sofrem inf1uência direta ou indireta de novos eventos, sugerem que a vida universitária interfere no desenvolvimento cognitivo dos estudantes. As alterações das características da estrutura cognitiva são determinadas por diversos fatores e considerando os resultados do presente estudo pode-se dizer que a experiência em Iniciação Científica pode ser um deles.

Em virtude da escassez da literatura sobre o assunto, torna-se necessário o desenvolvimento de outras pesquisas que investiguem, por exemplo, estudantes de cursos de diferentes áreas do conhecimento, de outras universidades e também os Estilos Cognitivos de orientadores e alunos.

Resultados destes estudos poderão ser transplantados para a prática, implementando-a. Por 
exemplo, as avaliações de Estilos Cognitivos podem ser utilizadas em processos seletivos de bolsistas de I.C. Entende-se que informações sobre os Estilos Cognitivos de candidatos aos programas de I.C. podem ser indicadores úteis, não no sentido de se excluir da possibilidade da experiência os que não apresentam os Estilos mais desejados, mas sim para que uma vez identificados possa-se valorizar as características do aluno e incentivá-lo a ousar. O professor poderá planejar atividades e estratégias visando ao enriquecimento do comportamento e do desempenho do aluno e, desse modo, estará contribuindo para o fortalecimento da versatilidade, o que facilitará a adaptação do estudante às diversificadas exigências da futura profissão.

Deve ser lembrado que o desenvolvimento da flexibilidade de Estilos Cognitivos é desejável, pois com isto o profissional tende a ser melhor sucedido (Curry, 1990; e Thompson e Crutchlow, 1993). A versatilidade de Estilos possibilita ao indivíduo adaptar-se mais facilmente às diferentes condições de aprendizagem, o que está de acordo com as diversas exigências da sociedade atual.

Assim sendo, entende-se que há necessidade de desenvolver pesquisas teóricas e empíricas que implementem as práticas e aprofundem a literatura disponível, uma vez que conhecimentos sobre Estilos Cognitivos podem ser úteis em diversos contextos.

\section{REFERÊNCIAS}

Allinson, C. W., Hayes, J. \& Davis, A. (1994) Matching the Cognitive Styles of Management Students and Teachers: A Preliminary Study. Perceptual and Motor Skills, 79, 1256-1258.

Bariani, I.C.D. (1998). Estilos Cognitivos de Universitários e Iniciação Científica. Tese de Doutorado. Faculdade de Educação da UNICAMP, Campinas, SP.

Bariani, I. C. D. \& Dimárzio, M. K. (1997) Perspectivas da Iniciação Científica por Estudantes Bolsistas de I.C. XXVII Reunião Anual de Psicologia, SBP, Ribeirão Preto, SP. (Não Publicado.)

Bettoi, S.M. (1995). O Pesquisar na Graduação: A Palavra do Aluno de Psicologia sobre as Condições Presentes na sua Vida Acadêmica. Dissertação de Mestrado, PUC-SP.

Costa, D. (1995) A Importância do Programa de Iniciação Científica para a Formação de Pesquisadores. Anais do I Encontro de Iniciação Científica da USF, 19-21.

Curry, L. (1990) A Critique of Research on Learning Styles. Educational Lidership, October, 50-56.

Gil, A C. (1991) Métodos e Técnicas de Pesquisa Social. São Paulo: Atlas.

Haim, G. (1981) Academic Ideologies and Styles of Research Among Academic Researchers. Research in Higher Education, 5, 291-303.

Messick, S. (1984) The Nature of Cognitive Styles: Problems and Prornises in Educational Practice. Educacional Psychologist, 19, 59-74.

Riding, J. R. \& Staley, A. (998) Seif-Perceprion as Learner, Cognitive Style and Business Studies Students' Course Performance. Assessment \& Evaluation in Higher Education, 23, 43-58.

Riding, R. J. \& Wright, M. (1995) Cognitive Style, Personal Characteristics and Harmony in Student Flats. Educational Psychology, 15,337-348.

Santos, A. A. A; Bariani, I. C. \& Cerqueira, T. C. S. (1998) Estilos Cognitivos e Estilo de Aprendizagem. In: F. F. Sisto (org.). Leituras de Psicologia para a Formação de Professores. Petrópolis, RJ, Vozes (no prelo).

Simão, L. M. (1994) Considerações sobre Formas de Relação entre Iniciação Científica e Pós-Graduação. $V$ Simpósio de pesquisa e Intercâmbio Científico, ANPPEP (MIMEO). 
Sternberg, RJ. \& Grígorenko, E. L. (1997) Are Cognítive Styles Stíll in Style? Amerícan Psychologist, 52, 700-712.

Thompson, C. \& Crutchlow, E. (1993) Learning Style Research: A Critical Review of the Literature and Implications for Nursing Education. Journal of Professional Nursing, 9, 34-40.

Zakon, A (1989) Qualidades Desejáveis na Iniciação Científica. Ciência e Cultura, 41,868-877.

Recebido em 18/12/2000

Revisado em 15/01/2001

Aprovado em 05/02/2001 